\title{
Éducation-Culture-Littérature, sous la direction d'Anne Bandry-Scubbi
}

\section{Gabriella Bosco}

\section{Q OpenEdition \\ 1 Journals}

\section{Edizione digitale}

URL: http://journals.openedition.org/studifrancesi/7780

DOI: ERREUR PDO dans/localdata/www-bin/Core/Core/Db/Db.class.php L.34 : SQLSTATE[HYO00]

[2006] MySQL server has gone away

ISSN: 2421-5856

\section{Editore}

Rosenberg \& Sellier

\section{Edizione cartacea}

Data di pubblicazione: 1 décembre 2009

Paginazione: 688-689

ISSN: 0039-2944

\section{Notizia bibliografica digitale}

Gabriella Bosco, «Éducation-Culture-Littérature, sous la direction d'Anne Bandry-Scubbi», Studi Francesi [Online], 159 (LIII | III) | 2009, online dal 30 novembre 2015, consultato il 07 janvier 2021. URL: http:// journals.openedition.org/studifrancesi/7780 ; DOI: https://doi.org/ERREUR PDO dans /localdata/ www-bin/Core/Core/Db/Db.class.php L.34 : SQLSTATE[HY000] [2006] MySQL server has gone away

Questo documento è stato generato automaticamente il 7 janvier 2021.

\section{(c) (i) $\odot$}

Studi Francesi è distribuita con Licenza Creative Commons Attribuzione - Non commerciale - Non opere derivate 4.0 Internazionale. 


\title{
Éducation-Culture-Littérature, sous la direction d'Anne Bandry-Scubbi
}

\author{
Gabriella Bosco
}

\section{NOTIZIA}

AA.VV, Éducation-Culture-Littérature, sous la direction d'Anne BANDRY-SCUBBI, «Universités/Domaine littéraire», série de l'Université de Haute-Alsace, Institut de Recherches en langues et littératures européennes, Orizons chez L'Harmattan, 2008, pp. 459.

1 Frutto di un convegno internazionale organizzato dall'Institut de Recherches en langues et littératures européennes (ILLE) tenutosi all'Université de Haute-Alsace dal 12 al 14 ottobre 2006 sotto la direzione di Anne Bandry-Scubbi e Laurent Berec, il volume ri-specchia in pieno la vocazione dell'équipe allo studio dell'identità letteraria europea, secondo una prospettiva che al nesso tra cultura e letteratura fonde quello tra formazione dell'individuo e trasmissione dei valori. I trenta contributi che lo compongono s'interessano alle aree culturali francofona, germanofona, italofona, ispanofona e anglofona, dall'antichità al xxI secolo. Gli autori sono in buona parte studiosi di letteratura, ma non mancano gli apporti provenienti da specialisti di discipline sorelle quali la storia, le scienze dell'educazione, la sociologia e l'antropologia, a prova del carattere risolutamente pluridisciplinare dell'impresa.

2 La prima delle due sezioni in cui sono organizzati i contributi, «Initiations», offre un'ampia riflessione intorno al termine e alla nozione di "Bildungsroman", con una serie di articoli dedicati a esempi di letteratura che raccontano l'educazione. Marie JOQUEVIEL BOURJEA studia l'evoluzione del racconto di formazione alla fine del xx secolo nei romanzi del poeta Jacques Réda, laddove la costruzione lineare è sostituita dalla visione caleidoscopica, apprendimento attraverso il disordine (Former le roman: "Aller au diable" de Jacques Réda, pp. 15-31). Lo stesso principio di frammentazione caratterizza le esperienze del personaggio di un fumetto americano disegnato da Winsor McCay e 
pubblicato tra il 1905 e il 1926 nel supplemento domenicale di due giornali newyorkesi - ogni episodio raccontava in un'unica tavola un sogno del ragazzino - di cui si occupa Jean-Paul MEYER (Les aventures de "Little Nemo in Slumberland": un «Bildungstraum»?, pp. 33-49, contributo arricchito dalla riproduzione di nove tavole del fumetto). Mentre un'evoluzione a ritroso è tratteggiata nei viaggi attraverso il tempo analizzati da Eric LYSøE in testi tardo ottocenteschi e della prima metà del XX secolo (Dernier clin d'œil à Eurydice: catabases initiatiques et voyages dans le temps, pp. 51-68). Suzanne VAN WEDDINGEN studia la maturazione di un personaggio dickensiano pusillanime durante un viaggio in treno le cui coincidenze prendono un valore metaforico (L'éducation du protagoniste dans "Barbox Brothers" et "Barbox Brothers \& Co." de Charles Dickens, pp. 69-77). E Dominique SIMON prosegue l'analisi di viaggi iniziatici occupandosi di un percorso da Berlino a Mosca coperto a piedi che si rivelerà una disillusione, ma attraverso il quale il protagonista scoprirà le virtù del camminare e dello spogliarsi progressivo di ciò che è superfluo (Wolfgang Büscher, "Berlin-Moscou, un voyage à pied": un Bildungsroman d'un genre nouveau?, pp. 79-89). E la disillusione è al centro anche del romanzo austriaco studiato da Régine BATTISTON, Mein Mörder, storia di un bambino senza educazione (Loin des clichés de l'enfance, ou "Mon Meurtrier" de Monika Helfer, pp. 91-105). Seguono poi alcuni contributi che mettono in relazione violenza e educazione: Georges GARY tramite lo studio di due novelle della romanziera americana Flannery O'Connor in cui figurano dei pedagoghi malmenati (L'enfer des bonnes intentions et le politiquement correct dans "The Barber" et "The Lame Shall Enter First" de Flannery O'Connor, pp. 108-119); Fabrice DE POLI e Felipe Aparicio NEVADO invece attraverso esempi di casi in cui a essere vittime sono degli allievi, il primo mostrando in numerosi romanzi e film della seconda metà del xx secolo - da Moravia a Moccia - le crudeltà dell'interrogazione (L'interrogation orale à l'école comme moment de crise: quelques exemples fournis par la littérature et le cinéma italiens, pp.121-134); il secondo raccontando l'educazione guerriera presentata in tre romanzi spagnoli post-franchisti (Reflets d'une éducation guerrière sous le franquisme, pp. 135-154). Di testi poetici nei quali invece la violenza appare trascesa grazie alla cultura si occupano Déborah HeISSLER (L'usage du blanc, et de cela que rien ne mesure: «Muzik, Muzik (...) il parlait de Mozart». Robert Antelme, L'espèce humaine, pp.155-163) e Nicole RocToN (L'empreinte biblique dans l'oeuvre de David Scheinert, pp. 165-174). Peter André BLосH studia il discorso pedagogico nietzscheano che teorizza l'appropriazione della cultura da parte dell'individuo affinché possa diventare «il capitano della propria vita» e farne una creazione (Nietzsche pédagogue, pp.175-188), e Peter SCHNYDER dimostra come un'analoga pedagogia liberatrice sia contemplata negli scritti di -Gide (Réflexions sur le rôle de la culture: l'exemple d'André -Gide, pp.189-197). Mentre Anne VAUCLAIR riflette sul modo in cui la pittura di Magritte spinge a superare le evidenze trasmesse dall'educazione attraverso la decostruzione che determina un'incertezza propizia a una nuova costruzione del sapere (La pédagogie de Fantômas, pp.199-210) e la curatrice del volume, Anne BANDRY-SCUBBI analizza un meccanismo molto simile nel Tristram Shandy, laddove Sterne mira a far prendere coscienza al lettore delle convenzioni che strutturano ogni testo e insegnargli così ad andare oltre la superficie ("Tristram Shandy" ou l'éducation du lecteur, pp. 211-222).

3 La seconda sezione s'intitola «Transmission» e si occupa del modo in cui le conoscenze e i valori legati a una cultura sono passati alle generazioni successive, a partire dal modello dell'educazione di Achille inteso come paradigma pedagogico di cui scrive Marie-France GINESTE (Le topos de l'éducation d'Achille dans la tradition littéraire de 
l'Antiquité tardive, pp.226-241); passando per l'esempio della legittimazione di un uso cristiano dell'eloquenza profana, analizzato da Céline URLACHER (L'attitude des chrétiens face à la culture classique, l'exemple d'Ennode de Pavie de la fin du ve siècle au début du vI, $\mathrm{pp}$. 243-259); poi per la costruzione di un discorso storico da parte di giornali e cronache all'inizio del xvi secolo con finalità didattiche volte alla coesione sociale, di cui s'interessa Myriam CHOPIN-PAGotTo (Nouvelle pédagogie pour un nouveau public de l'histoire: les récits des marchands au début du XvI siècle, pp. 261-273); e ancora per l'illustrazione della funzione pedagogica di una Bibbia in Yiddish degli inizi del xvII secolo studiata da Astrid STARCK-ADLER, testo che sentimentalizza la letteratura religiosa per adattarla al pubblico femminile ("La Tsennerenne", 1622, de Jacob ben Isaac Ashkenazi de Janow ou la Bible yiddish et l'éducation des femmes, pp. 275-290); e per gli emblemi come mezzo di accesso al sapere analizzati da Jean-Jacques CHARDIN (Pédagogie et expérience: quelques exemples dans l'emblématique anglaise des XVI et XVII siècles, pp. 291-305). Laurent CURELLY illustra poi il caso di un pastore poeta, George Herbert, che vorrebbe essere mediatore tra l'uomo e la conoscenza di Dio ma dispera della sua arte (La poésie de Georges Herbert. Entre pédagogie et mystique, pp. 307-317). Richard wiLson studia l'unica scena del teatro shakespeariano in cui figura uno scolaro - in The Merry Wives of Windsor - e illustra come l'apprendimento vi sia presentato come frutto di trasgressione più che di trasmissione (Just William Shakespeare's sentimental education, pp. 319-328). Mentre François LAROQUE studia le diverse sfaccettature dell'educazione dei principi nel Bildungsroman rappresentato dalla seconda tetralogia ( $F$ From a prince to a prentice». Éducation et apprentissage dans la seconde tétralogie de Shakespeare, pp. 329-343). Anticonvenzionale risulta essere anche l'educazione ricevuta da Nicolas Goulas, memorialista, affidato a pedagoghi che gli trasmisero cultura e senso del vivere sociale intrinsecamente congiunti, come spiega Mariette CUÉNIN-LIEBER (Les années d'apprentissage dans les Mémoires de Nicolas Goulas, 1603-1683, pp. 345-358). E Michel FAURE illustra il momento in cui, nel discorso sull'educazione in Gran Bretagna, emerge la letteratura, tramite la diffusione di periodici come lo "Spectator" («Education libérale» et culture littéraire au début du dix-huitième siècle en Grand-Bretagne, pp. 359-374). Analogo interesse per gli effetti educativi della letteratura si ritrova nel contributo di Marc WEISSER (Éduquer à la tolérance par la littérature de jeunesse: comparaison de deux discussions menées en fin d'école primaire, pp. 387-386). E Anne DEFFARGES, nella stessa direzione, analizza l'uso che la social-democrazia tedesca ha fatto della letteratura nelle sue lotte politiche di fine Ottocento, e i risvolti propagandistici di questo tipo di educazione (L'exemple de la socialdémocratie allemande: l'éducation par la littérature, pp. 387-400). E ancora di propaganda, ma come pedagogia dell'esemplarità, parla Frédéric CAILlE nel suo contributo a impronta sociologica in cui illustra la costruzione di un patrimonio morale attraverso il censimento sistematico di tutti gli atti di soccorso compiuti (À l'école des sauveteurs. Secours courageux et pédagogie de l'exemplarité civique et morale $\mathrm{XIX}^{e}-\mathrm{XX}^{e}$ siècles", pp. 401-412).

4 Viene poi anche affrontato il caso in cui la trasmissione di una cultura non riesce: Virginie ROCHE-TIENGO analizza una pièce del 1980 di Brian Friel in cui colui che insegna attraverso le lingue viene soppiantato dal traduttore-traditore che contribuisce alla scomparsa della sua stessa cultura (Éducation, littérature et transfert de culture dans "Translations" de Brian Friel, pp. 413-427). I romanzi di Tony Hillermann di cui scrive Claude NOSAL si rivelano invece ottime iniziazioni alla cultura per i giovani del popolo 
Navajo (Sur un air navajo, les ethno-polars d'initiation de Tony Hillermann, artisan des Dineh, pp. 429-448).

5 La considerazione conclusiva della curatrice riflette su come, accettando la presenza del multiplo nella ricerca del senso, la cultura del XxI secolo abbia fatto suo l'apprendimento attraverso il disordine evocato da numerosi dei trenta contributi raccolti i quali, a loro volta come un caleidoscopio, variano ciascuno a modo suo la combinazione della triade educazione-cultura-letteratura. 